\title{
Development of the Inventory Management and Tracking System (IMATS) to Track the Availability of Public Health Department Medical Countermeasures During Public Health Emergencies
}

Liora Sahar ${ }^{1}$, Guy Faler ${ }^{1}$, Emil Hristov ${ }^{1}$, Susan Hughes ${ }^{1}$, Leslie Lee ${ }^{2}$, Caroline Westnedge ${ }^{2 *}$ Benjamin Erickson ${ }^{3}$, Barbara Nichols ${ }^{4}$

1. Northrop Grumman Corporation (NGC), Information Systems, Atlanta, GA

2. SRA International, Inc., Atlanta, GA

3. Office of Public Health Preparedness and Response (OPHPR), Centers for Disease Control and Prevention, Atlanta, GA

4. Office of Public Health Scientific Services (OPHSS), Centers for Disease Control and Prevention, Atlanta, GA

\section{Abstract}

Objective: To bridge gaps identified during the 2009 H1N1 influenza pandemic by developing a system that provides public health departments improved capability to manage and track medical countermeasures at the state and local levels and to report their inventory levels to the Centers for Disease Control and Prevention (CDC).

Materials and Methods: The CDC Countermeasure Tracking Systems (CTS) program designed and implemented the Inventory Management and Tracking System (IMATS) to manage, track, and report medical countermeasure inventories at the state and local levels. IMATS was designed by CDC in collaboration with state and local public health departments to ensure a "user-centered design approach." A survey was completed to assess functionality and user satisfaction.

Results: IMATS was deployed in September 2011 and is provided at no cost to public health departments. Many state and local public health departments nationwide have adopted IMATS and use it to track countermeasure inventories during public health emergencies and daily operations.

Discussion: A successful response to public health emergencies requires efficient, accurate reporting of countermeasure inventory levels. IMATS is designed to support both emergency operations and everyday activities. Future improvements to the system include integrating barcoding technology and streamlining user access. To maintain system readiness, we continue to collect user feedback, improve technology, and enhance its functionality.

Conclusion: IMATS satisfies the need for a system for monitoring and reporting health departments' countermeasure quantities so that decision makers are better informed. The "user-centered design approach" was successful, as evident by the many public health departments that adopted IMATS.

Keywords: inventory management, countermeasures, public health emergency response events, pharmaceuticals, user-centered design.

Correspondence: rie7@cdc.gov

DOI: 10.5210/ojphi.v7i2.5873

Copyright @2015 the author(s)

This is an Open Access article. Authors own copyright of their articles appearing in the Online Journal of Public Health Informatics. Readers may copy articles without permission of the copyright owner(s), as long as the author and OJPHI are acknowledged in the copy and the copy is used for educational, not-for-profit purposes 


\section{Introduction}

\section{Background and Significance}

The Department of Health and Human Service's Centers for Disease Control and Prevention (CDC) and state and local public health departments share the responsibility to protect the public from negative health consequences resulting from terrorist attacks, natural disasters, or disease outbreaks. When such public health emergencies occur, it may be necessary for state and local public health departments to provide vaccines, pharmaceuticals and medical equipment (collectively referred to as medical countermeasures) to the public in order to save lives. If such an event were to affect large numbers of people, local supplies of medical countermeasures could be depleted quickly, putting persons at risk for illness or death. Accordingly, CDC has a plan to resupply state and local public health departments with medical countermeasures through its Strategic National Stockpile (SNS) [1]. "The SNS is a national repository of antibiotics, chemical antidotes, antitoxins, life-support medications, IV-administration, airway maintenance supplies, and medical/surgical items. The SNS is designed to supplement and re-supply state and local public health agencies in the event of a national emergency anywhere and at any time within the U.S. or its territories [1]". In addition, CDC advises state health departments to have primary and backup inventory management systems that can support responses to public health emergencies [2].

During a public health emergency, effective dissemination of medical countermeasures is crucial for a fast, efficient response. Supporting such efforts requires advanced planning, preparation and stockpiling [1,3-5], as was evident during the 2009 H1N1 influenza pandemic [6]. During this emergency, CDC and state and local public health departments found that they needed a way to better understand their medical countermeasure inventory quantities. Improved inventory awareness was needed all the way down to the local point-of-dispensing level. Decision makers felt they needed better countermeasure inventory information to help ensure they made the best choices on allocating and distributing antiviral drugs and personal protective equipment. During the $\mathrm{H} 1 \mathrm{~N} 1$ response, it was clear that state and local public health departments needed a comprehensive management system so they could accurately track and report their countermeasure inventory levels [7]. As a result, the CDC Division of Strategic National Stockpile (DSNS) partnered with the CDC Office of Public Health Scientific Service's (OPHSS) Countermeasure Tracking Systems (CTS) program to plan and build the Inventory Management and Tracking System (IMATS).

\section{Objective}

IMATS is a software application used to manage inventories of materials housed in warehouses or other storage facilities owned by or known to state and local public health departments. These inventories include medical countermeasures poised for distribution by public health departments during an emergency. The vision for IMATS was to increase the capacity at all levels of public health to accurately manage, track, and report the quantities of medical countermeasures needed to address a specific health threat. IMATS increases response readiness because it is useful for daily non-emergency inventory management operations. This enables users to become familiar with the system before an emergency response. When confronted by a public health crisis, decision makers need timely and comprehensive information that accurately describes the magnitude of the emergency, such as populations at risk, their location, and the availability of 
medical countermeasures. IMATS is designed to provide comprehensive information about medical countermeasure inventory available, locations of distribution facilities (i.e., state or regional warehouses, local storage facilities, etc.) and how much product has been used.

In this paper we provide an overview of events leading to the development of IMATS and a review of the system's design and implementation processes. We provide detailed descriptions of IMATS components and the role each plays in improving the capacity of public health officials to track and manage medical countermeasure inventory. The current adoption status of IMATS and proposed system enhancements also are presented.

\section{Materials and Methods}

\section{Partnerships and collaborations}

Following the 2009 H1N1 influenza response, DSNS partnered with the OPHSS CTS team to plan and build IMATS. In support of the cooperative agreement, Strengthen and Improve the Nation's Public Health Capacity through National, Non-Profit, Professional Public Health Organizations to Increase Health Protection and Health Equity, CDC formed the SNS Inventory Management and Tracking Workgroup. Workgroup members represented the Public Health Informatics Institute (PHII), DSNS, the OPHSS CTS team, and 10 state and local public health departments. The health department representatives were selected on the basis of their emergency response and inventory management expertise. Applying a user-centered design approach, the CTS team gathered user input by hosting online, virtual focus-group meetings, Webinars to define technical requirements, system demonstrations, in-person user experience and usability workshops, and conference presentations. Input from potential IMATS users was incorporated throughout each stage of development to ensure that IMATS met or exceeded user needs, preferences, goals and business objectives. Figure 1 depicts key partner-collaboration events occurring throughout the IMATS development process.

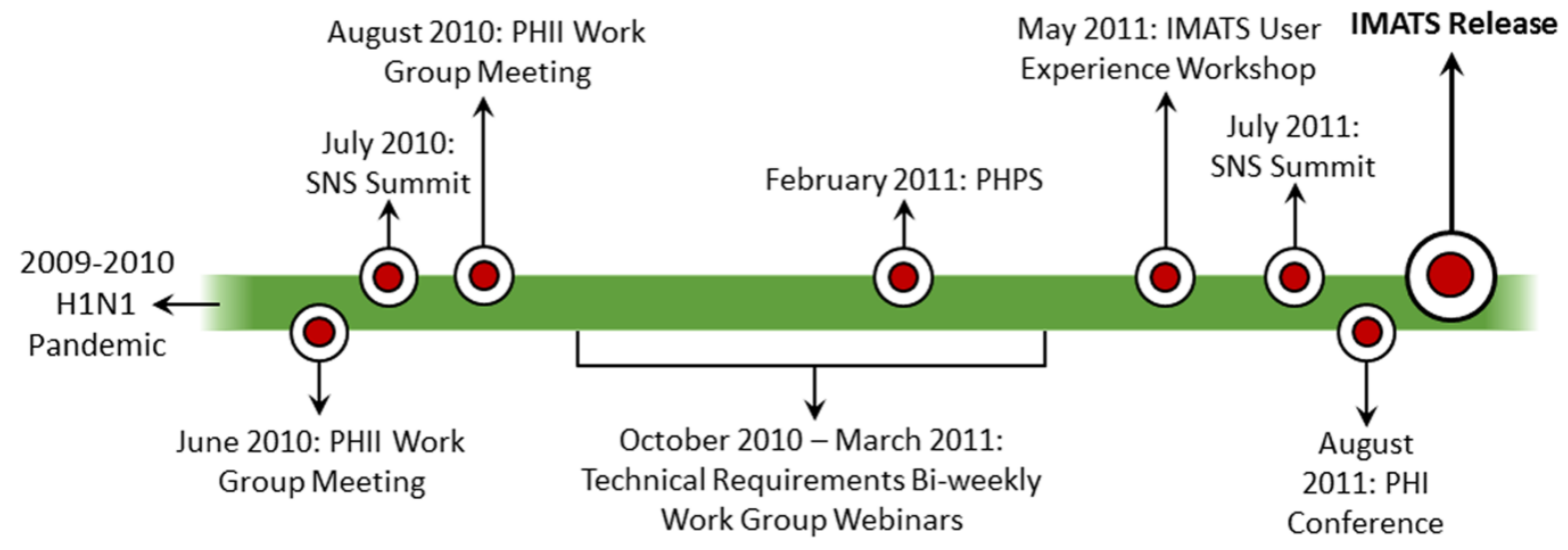

PHII: Public Health Informatics Institute PHPS: Public Health Preparedness Summit SNS: Strategic National Stockpile

PHI: Public Health Informatics

Figure 1: Key IMATS partner-collaboration events during program development 
The workgroup's objective was to develop high-level business processes and identify functional requirements to inform further development of the system. In June 2010, the workgroup kick-off meeting was held in Atlanta, Georgia. The meeting results included defining nine business processes that IMATS must support (Figure 2).

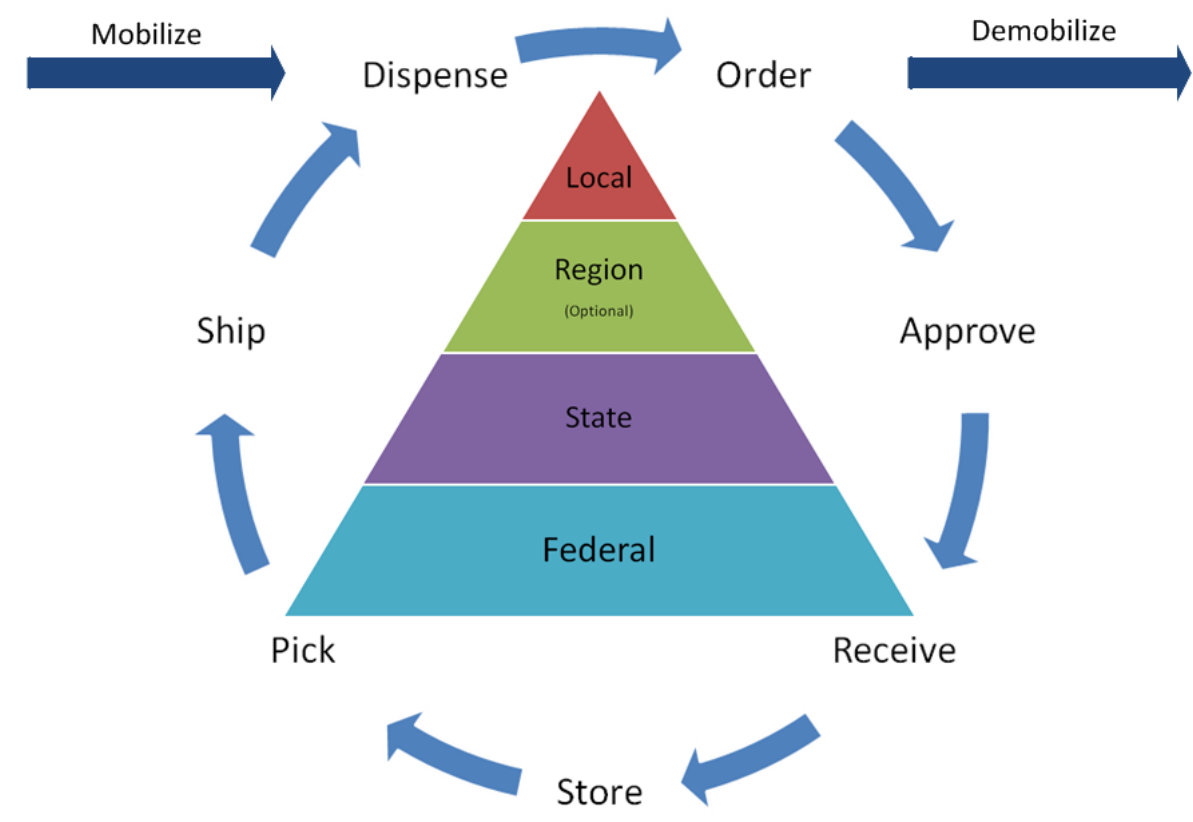

Figure 2: High-level public health inventory-management business processes

The workgroup reconvened in August 2010 to review, refine, and validate the nine business processes. To develop system requirements, the workgroup met biweekly with the CTS team from October 2010 to March 2011. During the 13 workgroup meetings, which were conducted via Webinar, the group gathered technical requirements, produced design layouts, and reviewed IMATS screen mockups.

From May 3-5, 2011, workgroup members participated in an in-person user-experience workshop held in Atlanta, Georgia. The objectives of this workshop were to refine user requirements, test system usability, and ensure required functionality was present. Participants were presented a public health emergency scenario with 18 tasks to complete by using a preproduction version of IMATS. By working through the task assignments, each user had multiple opportunities for comprehensive interaction with IMATS functionality. To acquire assessments of the greatest value, the participants were not provided IMATS training before performing their tasks. After completing the scenario tasks, participants recorded their assessments of IMATS and joined in productive open-group discussions. When this hands-on workshop ended, the CTS team was armed with valuable information that they incorporated into further IMATS development to help increase acceptance of the system.

In addition to the SNS Inventory Management and Tracking Workgroup, the OPHSS CTS team in collaboration with DSNS formed a Data Exchange Focus Group. The focus group included some members of the workgroup and representatives from state and local public health departments that purchased or developed their own inventory management systems. The focus group's objective was to develop an IMATS capability that would enable exchange of inventory 
data to CDC by those public health departments wishing to continue using their own inventory management systems. Focus group members met with the CTS team via Webinar on six occasions from April to July 2011. These meetings resulted in the creation of an Inventory Data Exchange (IDE) specification document.

Throughout the IMATS development cycle, CTS team members made multiple presentations and held poster sessions at various public health conferences. Those conferences also gave state and local public health representatives opportunities to ask questions of the CTS team and to describe their current inventory management needs and the limitations of their present systems. Their information proved highly useful for developing further IMATS refinements. The CTS team also launched a quarterly electronic newsletter in August 2010 to keep public health inventory managers nationwide informed about progress on IMATS development.

\section{System Requirements}

The set of requirements and constraints guiding IMATS development is described below.

\section{Requirements for Inventory Management and Tracking Processes}

To achieve the primary IMATS requirement to track and report medical countermeasure inventories during public health emergencies, the workgroup identified nine mandatory highlevel inventory management processes that IMATS must include. These processes all complied with DSNS guidance for receiving and redistributing medical countermeasures and for supporting routine operations at warehouses or other storage facilities. The first step in an emergency response is to mobilize required resources (Figure 2). The remaining processes are followed iteratively as necessary until the response effort ends and resources are demobilized.

From multiple Webinars and other discussions, the workgroup developed detailed requirements for IMATS that met the specific objective for each of the nine processes. The workgroup further suggested that IMATS be useful for daily operations in addition to public health emergency response activities. The workgroup determined that IMATS should provide support for analysis, visualization, and data reporting. The system also should support alternative means of data collection including import/export, bar-coding/scanning and Radio Frequency Identification (RFID) technology. These capabilities would make IMATS useful for routine inventory management activities. This, in turn, would increase users' system familiarity and alleviate the need for training during public health emergencies, which could delay starting emergency response operations. During public health emergencies, CDC may ask state and local public health departments to provide the agency with what amounts of specific medical countermeasures are needed to protect or treat people in their jurisdictions. IMATS was designed to aid fulfilling such requests by enabling users to easily produce the appropriate reports. Some workgroup members requested that in addition to its emergency response capabilities, the system would also have the ability to operate as a standalone system. As a result, an easy installer and synchronization mechanism was developed, as was a data exchange capability whereby inventory data can easily be reported to CDC. Table 1 provides details about the objectives of each process conducted by state and local public health departments.

Table 1: High-level public health inventory-management business processes

\begin{tabular}{|l|l|}
\hline Process & Objective \\
\hline Mobilization & Activate additional people and resources when response \\
\hline
\end{tabular}




\begin{tabular}{|c|c|}
\hline & $\begin{array}{l}\text { to an emergency has exhausted or nearly exhausted } \\
\text { existing resources }\end{array}$ \\
\hline $\begin{array}{l}\text { Order/Request } \\
\text { Resources }\end{array}$ & $\begin{array}{l}\text { Accurately and efficiently request needed resources on } \\
\text { the basis of meeting the jurisdiction's justification } \\
\text { criteria }\end{array}$ \\
\hline Approve/Deny Request & $\begin{array}{l}\text { Determine the validity of resource requests in a timely } \\
\text { manner }\end{array}$ \\
\hline Receive Inventory & $\begin{array}{l}\text { Physically receive, inspect and verify the accuracy of } \\
\text { newly received inventory within a specified time }\end{array}$ \\
\hline Store Inventory & $\begin{array}{l}\text { Identify appropriate storage locations and accurately } \\
\text { inventory all items to identify stock that is readily } \\
\text { available }\end{array}$ \\
\hline Pick Order & $\begin{array}{l}\text { Accurately pick and stage orders to be shipped to } \\
\text { another location }\end{array}$ \\
\hline Ship Inventory/Order & $\begin{array}{l}\text { Ensure timely delivery of assets regardless of barriers, } \\
\text { in accordance with federal, state and local requirements }\end{array}$ \\
\hline $\begin{array}{l}\text { Dispense Medical } \\
\text { Countermeasures }\end{array}$ & $\begin{array}{l}\text { Safely and accurately dispense appropriate medical } \\
\text { countermeasures to target populations }\end{array}$ \\
\hline Demobilization & $\begin{array}{l}\text { Secure remaining medical countermeasures and return } \\
\text { to normal operations }\end{array}$ \\
\hline
\end{tabular}

\section{Design Goals and Constraints}

In order to provide a system at no or little cost to partners and to support the above inventory system requirements, the set of design goals and constraints developed were that IMATS

- should be designed as a Web application and must be fully capable of being developed and distributed under an open source licensing model,

- must scale upwards to support hundreds or thousands of simultaneous users entering large volumes of data such as during an incident requiring mass prophylaxis,

- shall integrate with existing state and local public health inventory management systems,

- must support data exchange using Public Health Information Network (PHIN) [8] compliant messaging protocols,

- can be simultaneously deployed centrally at CDC and at state and local areas, and

- should require few as possible hardware and processing assets and be database independent.

\section{System Design and Development}

IMATS is intended to have an easy and intuitive user interface that encourages its use and helps increase system adoption. IMATS must also adhere to the access and use requirements in Section 508 of the Rehabilitation Act of 1973 (http://www.section508.gov) requiring that when Federal agencies "develop, procure, maintain, or use electronic and information technology, Federal employees with disabilities have access to and use of information and data that is comparable to 
the access and use by Federal employees who are not individuals with disabilities, unless an undue burden would be imposed on the agency".

The IMATS security approach was developed with the assistance of CDC business, technical and security stewards to be compliant with federal regulations. When the application is deployed centrally at CDC, user registration and authentication is managed by CDC security processes and tools. IMATS is a secure Web-based application that limits user access to functions and data by means of role-based security authorization. Database access control is governed by public health jurisdiction or organization ownership.

\section{Technology and Development Tools}

IMATS is a typical Java 2 Platform, Enterprise Edition (J2EE) Web application. It has a 3-tier architecture in which each application tier is composed of one or more layers of code. Figure 3 shows the tiers and the layers associated with each tier. 


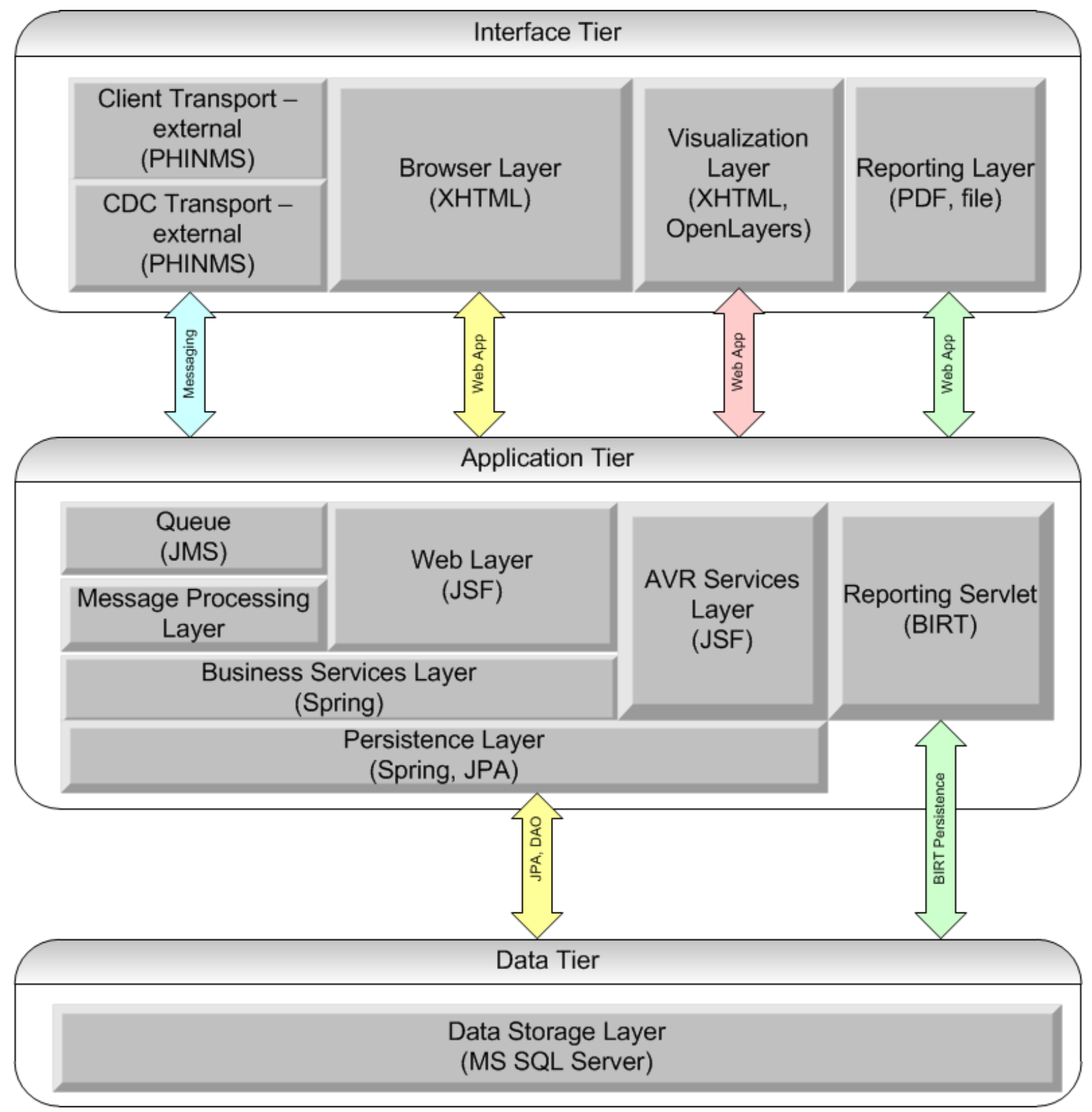

Figure 3: IMATS 3-Tier Architecture

IMATS database design followed the concept of database independence to provide maximum portability. For example, stored procedures were avoided and naming conventions were standardized. The system is currently using SQL server 2008 enterprise standard edition for the CDC centrally deployed application, and either SQL Server Express or H2 databases for standalone deployment.

\section{Development and Design Process}

Project management, design and development followed Scrum and Agile methods [9]. Agile methods refer to iterative, incremental, near-term development cycles (sprints). These enable short and regular feedback loops from customers who can see regular, tangible results [10]. Agile 
methodology supports "user-centered" development and requires that a customer be involved throughout the life cycle of the project.

Risk mitigation was accomplished through several methods. One such method was stakeholder identification. Because CDC is a large organization, communicating the vision of the project to CDC leadership allowed the team to secure necessary approvals, refine project scope, and identify other stakeholders. The 10 state and local public health departments of the workgroup were selected based on their expertise in preparedness and response but also on characteristics of the jurisdiction they represented including location, population, budget, and technical expertise. The resulting workgroup reflected national needs and established solid requirements for development. Further risk management processes included strict adherence to Agile methodology principles such as direct communication between users and the development team, daily stand-up meetings to exchange ideas, and recurring sprint reviews with demonstrations to stakeholders and users.

The Agile methodology and risk mitigation methods provided frequent opportunity for users and stakeholders to change requirements and direction or affirm project development was proceeding according to schedule and cost baselines [11]. During the development cycle, no requests for additional funding were made and staffing levels remained constant throughout. This controlled development process allowed IMATS to be launched by the scheduled release date.

\section{Trial period}

The "user-centered design approach," which focuses on interleaving design and development efforts, continued even after the initial release of IMATS. Public health partners were encouraged to use the system during trial periods before moving forward with the adoption process to ensure IMATS met their needs. Those participating in a trial period were granted full access to the trial system for 30 days. The trial instance of IMATS was set up in partnership with the Informatics Innovation Unit at CDC, and an email-based "help desk" was created so users could send questions and suggestions. The development team evaluated requests for enhancements and prioritized those selected for implementation.

After public health partners completed the trial period, they received implementation guidance and were asked to complete a Web-based survey. The survey consisted of 26 multiple choice and short answer questions. The questions were designed to gather information about the

- effectiveness of the communication methods used to promote IMATS availability;

- effectiveness of the IMATS trial period;

- identification of decision criteria for IMATS adoption;

- satisfaction level of current inventory management system (not including IMATS);

- identification of inventory management systems in use; and

- perceived ability of IMATS to meet the user's needs.

The survey was distributed to 96 public health departments on August 20, 2012. Forty-one responses (43\%) were received by the August 31 deadline, covering 17 state- and 24 local-level public health departments. This activity was not research involving human subjects and did not require institutional review board (IRB) approval. 


\section{Results}

\section{IMATS System Description}

IMATS enables public health officials to track medical countermeasure inventory during both everyday operations and public health emergencies. State and local public health department users can track quantities of inventory, monitor reorder thresholds and facilitate warehouse operations such as inventory receiving, staging, and storing. To use IMATS to perform these and other inventory management functions, users access the system's Web-based interface and enter product, location, quantity and other data. Listed in Table 2 are major system features accompanied by brief descriptions.

Table 2: High-level public health inventory management system features

\begin{tabular}{|c|c|}
\hline IMATS Feature & Description \\
\hline Product Information & $\begin{array}{l}\text { Includes prepopulated product and supplier data from the FDA } \\
\text { approved drug products list (the Orange Book). Enables users to add } \\
\text { individual items or perform bulk upload of additional product and } \\
\text { supplier data into IMATS as they receive these products at their } \\
\text { warehouses. }\end{array}$ \\
\hline Setup & $\begin{array}{l}\text { Establishes data-import capabilities about users, products, suppliers, } \\
\text { product units of measure, locations within a warehouse and current } \\
\text { inventory data. Manual configuration allows users to key in } \\
\text { information about new facilities, custom-user roles and funding } \\
\text { sources for countermeasures stored in each warehouse. }\end{array}$ \\
\hline $\begin{array}{l}\text { Inventory } \\
\text { Management }\end{array}$ & $\begin{array}{l}\text { Supports warehouse activities by enabling users to complete purchase } \\
\text { order, back order, receive, put away, pick, ship, and import push } \\
\text { package operations and complete other inventory functions as needed } \\
\text { at each warehouse. }\end{array}$ \\
\hline Reporting & $\begin{array}{l}\text { Provides public health partners with reports of warehouse operations, } \\
\text { available in PDF or Excel format. Types of reports include: } \\
\text { - Count Inventory Report: provides current stock levels plus } \\
\text { request and shipment information for selected products } \\
\text { - Audit Trail Report: provides detailed information on all } \\
\text { transactions in the system } \\
\text { - Inventory Reports: enables public health partners to provide } \\
\text { inventory status to CDC during public health emergencies }\end{array}$ \\
\hline $\begin{array}{ll}\text { Inventory } & \text { Data } \\
\text { Exchange (IDE) } & \end{array}$ & $\begin{array}{l}\text { Provides electronic data exchange interfaces, standards and } \\
\text { specifications for public health partners to electronically transmit to } \\
\text { CDC data files showing state and local public health jurisdictions' } \\
\text { inventory levels. Allows data transfer from local public health } \\
\text { departments to the state level and then to CDC regardless of the } \\
\text { inventory management system in place. Data transfer is performed by } \\
\text { conventional import/export functionality using standard protocols } \\
\text { (e.g., HL7, XML, etc.). }\end{array}$ \\
\hline Synchronization & $\begin{array}{l}\text { For local deployments of IMATS, allows communication and data } \\
\text { transfer between two instances of IMATS. For example, from a local } \\
\text { instance of the application to a state level or other centralized instance. }\end{array}$ \\
\hline
\end{tabular}


The current implementation is based on a client-server paradigm in which client instances of IMATS can synchronize their data with a preconfigured parent IMATS server instance. The synchronization mode can be automatic with preconfigured intervals of time, or manual via the IMATS user interface.

\section{Trial Period and Adoption}

State and local public health partners were encouraged to participate in a 30-day IMATS trial period before adopting the system. In October 2011, the first month the trial site was available, 31 public health departments (9 state, 22 local) began an IMATS trial period. By September 30, 2012, a year after IMATS’ release, 102 public health departments (27 state, 75 local) completed an IMATS trial period. Thirty-six public health departments (16 state, 20 local) adopted IMATS as their primary or backup system. As of June 2015, 27 state and 38 local public health departments have implemented IMATS. Four of the implementations are statewide (implementation at the state and all local public health departments). By June 2015, the CTS help desk at CTSHelp@cdc.gov responded to 2804 user inquiries and received 94 enhancement requests, of which 44 are implemented thus far.

According to results of the survey, the most effective vehicles of communicating the availability of IMATS were interaction with the state-level SNS coordinators (46\%) and publication of the IMATS quarterly newsletter (56\%). About $85 \%$ of respondents said the IMATS trial period was helpful in deciding whether to adopt IMATS. The top three adoption-decision criteria varied among state and local public health departments. States indicated (in descending order) cost, availability, and incident response suitability as their leading criteria. Local public health departments cited cost, ease of use, incident response suitability, and efficiency as the leading factors. Whereas cost is a major concern at all levels of government, the need for a system that can be successfully used during an incident response was consistently a leading assessment factor. Only $15 \%$ of respondents indicated they were not satisfied with the value IMATS provides as an inventory management system (Figure 4a). The majority of respondents indicated IMATS met their expectations for a medical countermeasure inventory tracking system (Figure 4b), and that it has sufficient functionality and features to track inventory during a public health emergency (Figure 4c).

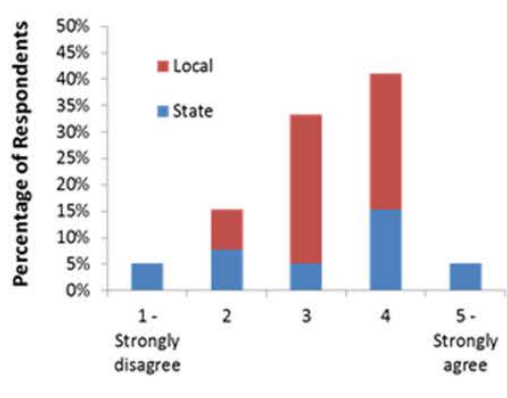

(a)
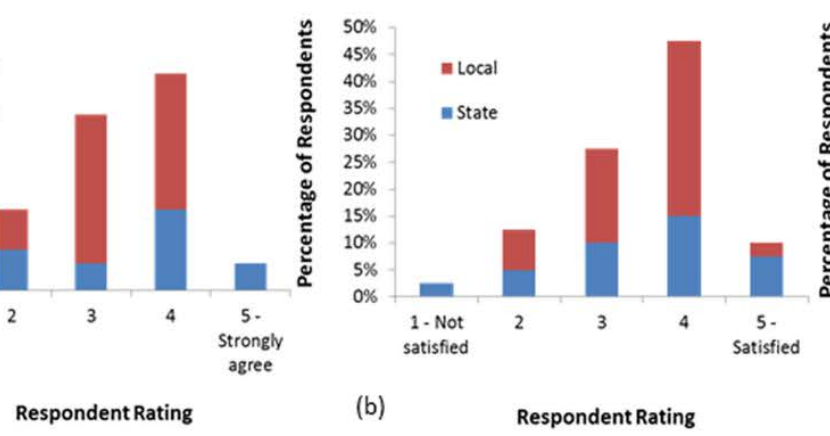

(b)

Respondent Rating

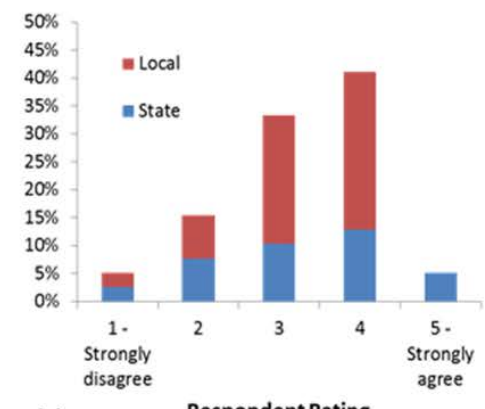

(c)

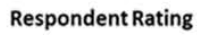


Figure 4: $\mathrm{X}$ axis (respondent rating) $\mathrm{Y}$ axis (percentage of respondents). (a) Ratings of IMATS features to track inventory during an event response. (b) Satisfaction with the value of IMATS. (c) IMATS meets expectations as an inventory management system

The Public Health Preparedness Capabilities: National Standards for State and Local Planning states in order to receive medical countermeasures, public health departments should "have or have access to a system (hardware and software) to receive and manage inventory.” In addition, the "system must also have a backup which can be inventory management software, electronic spreadsheets, or paper [2].” Public health departments can choose whichever system they wish for inventory tracking; they are not required to use IMATS. To help the CTS team understand the current system status of those public health departments interested in adopting IMATS, respondents to the survey mentioned earlier were asked to identify both the primary and backup inventory management system (Figure 5) they currently use. Eight percent of respondents indicated they do not have a primary system. The majority (70\%) with a primary system invested in a home-grown electronic inventory management system. Only $23 \%$ of all respondents indicated they were satisfied with their primary system. Regarding a backup system, about 85\% of respondents indicated they had no backup system in place or were using Access, Excel, or pen and paper. Only $20 \%$ of the respondents indicated they were satisfied with their backup system.
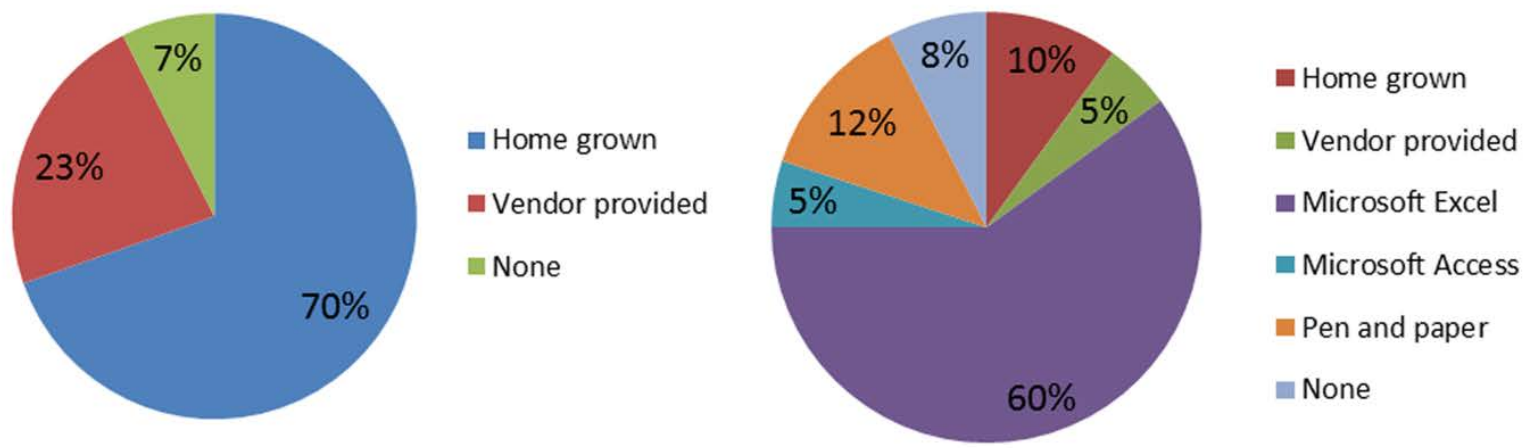

Figure 5: Types of Inventory Management systems in use. Primary (Left). Backup (Right)

\section{Discussion}

During a public health emergency, accurately reporting medical countermeasure inventory data provides CDC's DSNS with an understanding of the types and quantities of medical countermeasures available at state and local health departments. The specific countermeasure data reported are unique and vary according to the nature of each emergency. IMATS is a flexible system that can manage data about any type of inventory. The state and local countermeasure inventory data managed and reported through the use of IMATS better informs decision makers about medical countermeasure availability and resupply needs.

IMATS is a user-friendly system designed to support public health emergency responses as well as daily operations. Daily use fosters in-depth familiarity with the system to help ensure smooth 
and efficient responses during public health emergencies. IMATS was developed in partnership with its end users in order to tailor the system to maximally support the needs of public health. IMATS is a free solution that is maintained, updated, and provided to users at no cost.

A high percentage (85\%) of respondents indicated they are using Access, Excel, or pen and paper for their backup system or have no backup system in place. That statistic suggests there is considerable potential for many to adopt IMATS as their backup system. In addition, since only $23 \%$ of respondents were satisfied with their current system, IMATS is a particularly viable option for public health departments ready to adopt a new inventory management system. Accordingly, it is important to keep those public health departments not using IMATS well informed about improvements to the system and its uses. This can be accomplished through state-level SNS coordinators, continuing to publish the quarterly IMATS-update newsletter and discovering additional effective means of communication.

\section{Limitations and Future Work}

It is important that IMATS continually improve its functionality so it can adapt to changing user needs and technology advancements. Currently, IMATS lacks the capability to support barcode scanning and system access via mobile devices. The CTS team is exploring ways to incorporate these advanced technologies, which may interest jurisdictions that have not yet implemented the system. To comply with security requirements, user identity must be verified before system access is allowed. During a public health emergency, delays in onboarding new users and volunteers could slow the response effort.

To help alleviate these delays, IMATS Connect was developed to give jurisdictions full control of the user enrollment process and security of both IMATS and the data it contains. IMATS Connect is a standalone version of IMATS available for jurisdictions to download, install, and maintain. Alternatives that would accelerate the access process continue to be explored. IMATS is a comprehensive inventory management system designed to meet the specific needs of state and local public health departments. It does not, however, provide the means to track the administration of countermeasures to people. To capture these data, state and local public health departments often rely on state vaccine registries or other systems.

The IMATS team continues to work closely with stakeholders to improve IMATS so that it provides increasingly better support to CDC and state and local public health departments. Our efforts to continue user engagement and to maintain system readiness increases the public health community's preparedness for effective responses to future public health emergencies.

\section{Conclusion}

IMATS supports emergency response efforts by enabling rapid and accurate data collection and reporting of public health departments' medical countermeasure inventory down to the local point-of-dispensing level. The development and release of IMATS provides state and local public health departments with an effective solution to help bridge the inventory data gaps identified during the H1N1 pandemic.

The "user-centered design approach" used to develop IMATS is successfully providing public health partners nationwide with a system that meets their inventory management and tracking requirements. IMATS continues to be adopted by both state and local public health jurisdictions. Many jurisdictions that have adopted IMATS now incorporate it into their preparedness 
exercises. Survey results show that a majority of IMATS adopters believe the system provides sufficient functionality and features to track inventory during public health emergencies. These findings are important, as survey results also indicate that only $23 \%$ of respondents were satisfied with their current non-IMATS primary inventory management system. The combination of survey results showing a high level of user satisfaction and the adoption of IMATS by 65 public health departments (27 state, 38 local) highlights the system's usefulness as an effective medical countermeasure inventory management and tracking tool. The proven "user-centered design approach" is still being applied to enhance the system. Combined with continued support from DSNS as the program sponsor, IMATS continues to evolve and better support the needs of public health partners.

\section{Acknowledgements}

The authors thank the Public Health Informatics Institute and members of the SNS Inventory Management and Tracking Workgroup for their important contributions to developing IMATS.

The findings and conclusions in this report are those of the authors and do not necessarily represent the official position of the Centers for Disease Control and Prevention.

\section{References}

1. Centers for Disease Control and Prevention. Strategic National Stockpile (SNS). c2012 [updated 2012 Oct; cited 2013 Aug 26]. Available from: http://www.cdc.gov/phpr/stockpile/stockpile.htm.

2. U.S. Department of Health and Human Services, Centers for Disease Control and Prevention. Public Health Preparedness Capabilities: National Standards for State and Local Planning 2011. [cited 2013 April]; Available from: http://www.cdc.gov/phpr/capabilities/DSLR_capabilities_July.pdf.

3. McCoy JH, Brandeau ML. 2011. Efficient stockpiling and shipping policies for humanitarian relief: UNHCR's inventory challenge. OR-Spectrum. 33, 673-98. http://dx.doi.org/10.1007/s00291-011-0237-4

4. Adida E, Delaurentis PC, Lawley MA. 2011. Hospital stockpiling for disaster planning. IIE Trans. 43(5), 348-62. http://dx.doi.org/10.1080/0740817X.2010.540639

5. Lin C, Lin CM, Yen DC, et al. 2012. The Integrated Information Architecture: A Pilot Study Approach to Leveraging Logistics Management with Regard to Influenza Preparedness. $J$ Med Syst. 36(1), 187-200. PubMed http://dx.doi.org/10.1007/s10916-010-9458-3

6. Cannava P, Cicillini D, Higgins M, et al. 2010. Response to H1N1 Influenza Outbreak in a Pediatric Children's Hospital: Challenges Faced and Lessons Learned. J Pediatr Nurs. 25(5), 375-81. PubMed http://dx.doi.org/10.1016/j.pedn.2010.03.001

7. Managing Antiviral Medication during the 2009 H1N1 Influenza Pandemic: State and Local Public Health Department Responsibilities. [cited 2014 July]; Available from: http://www.astho.org/Programs/Infectious-Disease/Antiviral-Distribution/ManagingAntiviral-Medication-during-the-2009-H1N1-Influenza-Pandemic/. 
8. Centers for Disease Control and Prevention. PHIN Messaging. c2011 [Updated 2011 Mar 31; cited 2013 Aug 26]. Available from: http://www.cdc.gov/phin/activities/messagingtransport.html.

9. Abrahamsson P, Salo O, Ronkainen J, Juhani W. Agile software Development Methods Review and analysis. VTT Publications; 2002.

10. Schuh P. Integrating Agile Development in the Real World. Thomson; 2005.

11. Schwaber K. Agile Project Management with Scrum. Microsoft press; 2003. 